\title{
Dissolution Kinetics of Zinc Oxide Ore with an Organic Acid
}

Jiushuai Deng*, Quanwei Sun, Peijia Lin, Guojun Song, Shuming Wen, Jianying Deng and Dandan Wu*

State Key Laboratory of Complex Nonferrous Metal Resources Clean Utilization, Faculty of Land Resource Engineering, Kunming University of Science and Technology, Kunming 650093, PR China

\section{Abstract}

In this study, the dissolution kinetics of smithsonite as an alternative zinc source in trichloroacetic acid (TCA) solution was investigated. TCA can be derived from industrial waste acid in the pharmaceutical, biotechnology and chemical fields. Results showed that the dissolution kinetics conformed to the shrinking core model controlled by surface chemical reaction. The apparent activation energy of the reaction was calculated as $47.61 \mathrm{~kJ} / \mathrm{mol}$, indicating the obvious effect of temperature on the reaction rate. The reaction kinetic equation associated with the main influencing factors was eventually established as 1$(1-\mathrm{x})^{-1 / 3}=\left[0.0002(C)^{0.384}(P)^{0.969} \exp (-5726 T)\right] \mathrm{t}$. The high reaction speed of smithsonite in TCA solution shows that TCA has a dissolution effect on zinc oxide ores; thus, it can be employed as an advantageous organic leaching reagent environmentally friendly. In addition, the experimental parameters obtained provide basic data and reference for the leaching of other carbonate minerals of copper, zinc, lead and cobalt, among others, in an organic acid system.

\section{Introduction}

Zinc is an extensively used significant non-ferrous metal. In nature, zinc ores could be divided into sulphide minerals and oxide minerals. Sulphide minerals include sphalerite $(\mathrm{ZnS})$ and marmatite $\left(\mathrm{Zn}_{\mathrm{x}} \mathrm{Fe}_{1-}\right.$ $\mathrm{S})[1]$, whereas carbonate and silicate minerals, such as smithsonite $\left(\mathrm{ZnCO}_{3}\right)$, hydrozincite $\left(2 \mathrm{ZnCO}_{3} \cdot 3 \mathrm{Zn}(\mathrm{OH})_{2}\right)$, hemimorphite $\left(\mathrm{Zn}_{4} \mathrm{Si}_{2}\right.$ $\left.\mathrm{O}_{7}(\mathrm{OH})_{2} \cdot \mathrm{H}_{2} \mathrm{O}\right)$, zincite $(\mathrm{ZnO})$ and willemite $\left(\mathrm{Zn}_{2} \mathrm{SiO}_{4}\right)[2,3]$, are classified as oxide minerals. Zinc oxide minerals are widely distributed, especially in China and Turkey. Given the increasingly depleted sulphide mineral resources, zinc oxide minerals have become significant alternatives for sulphurous ores $[4,6]$. Techniques for extracting zinc from its oxide ores continue to evolve.

Intensive studies on metal extraction from ores are necessary to keep up with the increasing demand for metals. Zinc oxide ores are subjected mainly to two treatments, namely, pyrometallurgy and wet metallurgy $[7,8]$. The former brings about serious environmental pollution, whereas the latter, with favourably high metal leaching rate and low cost, could better satisfy environmental requirements [9]. Two principal hydrometallurgy technologies, alkali and acid leaching, can be used for zinc oxide ores. Alkaline gangues (such as $\mathrm{Cao}$ and $\mathrm{MgO}$ ) and silicon gangues (such as $\mathrm{SiO}_{2}$ ) account for large proportions in zinc oxide ores, and valuable metals coexist with numerous metal impurities. Hence, alkali leaching of zinc oxide ores has been investigated by previous researchers based on the amphiprotic characteristic of zinc, i.e., it does not only dissolve in acid but also reacts with alkali. Depending on the type of leaching reagents, alkali leaching can be grouped into ammonia leaching and superalkali leaching, with ammonium or sodium hydroxide as the main leaching reagents [10].

Treatment of zinc oxide ores (including high-silicon zinc oxide ores) directly by acid leaching has been investigated in multiple countries to obtain qualified zinc solutions and produce zinc metal by electro winning. Inorganic acids, such as sulphuric acid, have been applied as leaching reagents in these studies $[9,11,12]$.

In addition to inorganic acids, organic acids have also been employed as leaching reagents $[6,13]$. Glucose acid was used by Hurşit [6] as leaching reagent for zinc oxide ores, and citric acid was applied by Shabani [14] for oxide ores. The results from previous studies indicated that organic acids, such as citric acid, acetic acid and glucose acid, could be employed as beneficial leaching reagents [15]. Their aqueous solutions are all mildly acidic [15-17]. A leaching solution with low impurity content could be obtained by mild acids and their salts because of the dissolution selectivity of minerals [18].

Based on the reasons presented above, new organic leaching reagents for zinc extraction are worth examining. TCA is an organic compound with the chemical formula $\mathrm{CCl}_{3} \mathrm{COOH}$, which exhibits greater acidity than acetic acid because of the electron-withdrawing effect of chlorine. It is primarily used as an intermediate for organic synthesis, pharmaceutics, pesticides and chemical reagent preparations, as well as a precipitant for macromolecular compounds, such as proteins, DNA and RNA $[19,20]$. Thus, in the pharmaceutical, biotechnology and chemical fields, a lot of waste acid products (TCA) are generated, which are harming the environment. In the present work, these waste acids are used for recovery of zinc. The comprehensive utilization of these waste acids can not only save resources and protect the environment, but also create a good economic value. However, no leaching reagent for zinc extraction from zinc ores has been reported thus far.

Smithsonite is an important mineral with large reserves among zinc oxide ores, which can be generated through metasomatism between zinc sulphate. It is a secondary mineral in the oxidation zone, often found together with malachite, azurite, hemimorphite, hydrozincite, galena and cerussite. Given that smithsonite can be applied as an alternative ore, it was adopted as the research object in this study. Research literature on the dissolution kinetics of smithsonite $[5,21]$ are rare.

\section{"Corresponding Author:}

Jiushuai Deng, State Key Laboratory of Complex Nonferrous Metal Resources Clean Utilization, Faculty of Land Resource Engineering, Kunming University of Science and Technology, Kunming 650093, PR China; E-mail: dengshuai689@163.com

Dandan Wu, State Key Laboratory of Complex Nonferrous Metal Resources Clean Utilization, Faculty of Land Resource Engineering, Kunming University of Science and Technology, Kunming 650093, PR China; E-mail: wdd1006530@sina.com

Citation: Deng J, Sun Q, Lin P, Song G, Wen S, et al. (2015) Dissolution Kinetics of Zinc Oxide Ore with an Organic Acid. Int J Metall Mater Eng 1: 109. doi: http:// dx.doi.org/10.15344/2455-2372/2015/109

Copyright: ( 92015 Deng et al. This is an open-access article distributed under the terms of the Creative Commons Attribution License, which permits unrestricted use, distribution, and reproduction in any medium, provided the original author and source are credited. 
Citation: Deng J, Sun Q, Lin P, Song G, Wen S, et al. (2015) Dissolution Kinetics of Zinc Oxide Ore with an Organic Acid. Int J Metall Mater Eng 1: 109. doi: http://dx.doi.org/10.15344/2455-2372/2015/109

Page 2 of 7

Leaching is the first step in the metallurgical route, and from the economic perspective, the leaching kinetics is significant. Thomas [22] investigated zinc oxide ore leaching with chlorine and chlorine hydrate, and found that the leaching rate was controlled by surface reaction. In another study, the application of organic acid as leaching reagent was investigated. The dissolution kinetics of smithsonite in an aqueous solution of glucose acid under specific influencing factors in a reactor was studied. The stirring speed was found to have no effect on the dissolution rate. The apparent activation energy of the process was $47.92 \mathrm{~kJ} / \mathrm{mol}[6]$.

The current research was designed to study for the first time the dissolution kinetics of smithsonite with TCA as the leaching reagent and to optimise smithsonite-leaching conditions. Moreover, the effects of specific parameters, such as temperature, acid concentration, particle size and stirring speed, on zinc leaching were investigated. Furthermore, a corresponding chemical reaction-controlling model was obtained, which adequately explained the relationship between the reaction time and the zinc-leaching rate. Finally, the apparent activation energy of the process was determined.

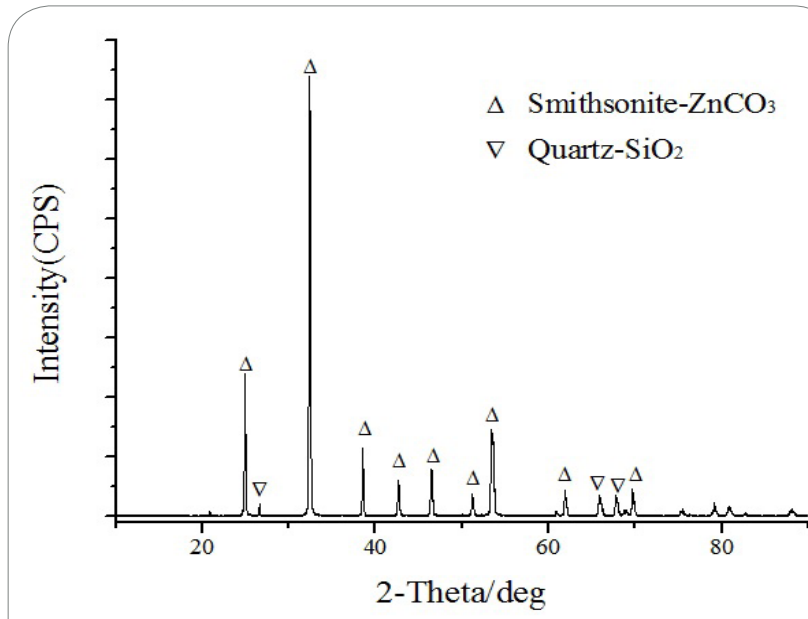

Figure 1: XRD pattern of zinc oxide ore.

\section{Experimental}

\section{Material and methods}

The experimental raw materials were obtained from Yunnan, China. Ores with high-grade zinc were picked out, crushed, and screened. Ore samples with average particle size of $2 \mathrm{~mm}$ were obtained as experimental materials. To test the composition, X-ray diffraction (XRD) and chemical analysis were conducted using an XRD tester (NSK D/max model) with CuKa target $(\lambda=1.5406 \AA$ ) working at 40 $\mathrm{kV}$ voltage, $40 \mathrm{~mA}$ current and $10^{\circ}$ to $90^{\circ}$ scanning range. The XRD pattern in Figure 1 shows that the experimental ore sample was mainly composed of smithsonite and quartz. The chemical analysis results are presented in Table 1, showing that $\mathrm{Zn}$ and $\mathrm{SiO}_{2}$ accounted for $44.2 \%$ and $5.53 \%$ of the ore, respectively. Nonetheless, the zinc oxide ore was mainly composed of smithsonite. The scanning electron microscope (SEM) and energy dispersive spectroscopy (EDS) images of the experimental ore sample obtained by Philip XL30 scanning electron microscope are presented in Figure 2. Figure 2 shows the morphology and the main constituent of the mineral. The EDS analysis result and the chemical analysis result are consistent.

In the experiment, deionised water with resistivity of $18 \mathrm{MQ}$, which was prepared using a Milli-Q5O water-purifying instrument from the USA, was applied as the leaching solvent. The TCA from Xinhui Chemical Engineering and Commercial Co., Ltd., Tianjin, China was analytically pure.

\begin{tabular}{|l|l|l|l|l|l|}
\hline Component & $\mathrm{Zn}$ & $\mathrm{SiO}_{2}$ & $\mathrm{CaO}$ & $\mathrm{Al}_{2} \mathrm{O}_{3}$ & $\mathrm{Fe}$ \\
\hline Content (\%) & 40.21 & 5.53 & 1.37 & 0.64 & 1.15 \\
\hline
\end{tabular}

\section{General procedure}

A set of compound device for leaching (Figure 3), hereby referred to as CDL, was specifically designed and customised by ZBR Instrument Co., Ltd. in Jiangsu, China. In this researcher-designed leaching device, eight reactor units were innovatively placed into a thermostatic water bath, each connected to a three-mouth flask.

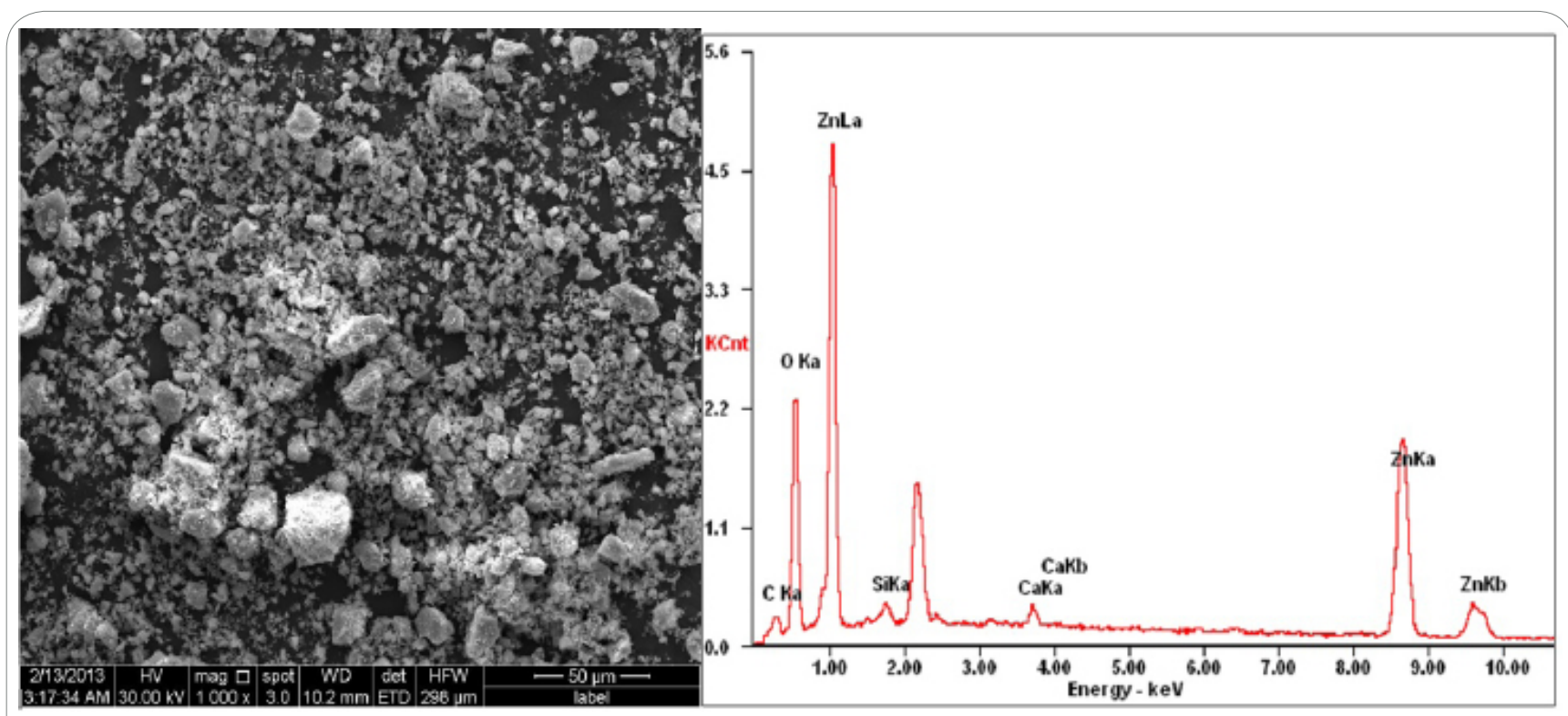

Figure 2: SEM-EDS images of the experimental zinc oxide ore. 
For each flask, a serpentine condenser pipe and a mechanical stirrer were placed in two of its mouths. The third mouth was used for sample filling and solution extraction, blocked off with a ground stopper. In the CDL, the eight condenser pipes were connected by rubber tubes from end to end. They were then connected to a water inlet and a outlet for the condensation of the steam generated during the experiment. Overall, the whole CDL consisted of one water bath, eight threemouth flasks, eight mechanical stirrers, and eight condenser pipes. A number of non-stop magnetic stirrers were placed at the bottom of the water bath to make the liquid homogeneous. Moreover, the water bath was equipped with an automatic temperature controller, and the mechanical stirrers had adjustable rotating speed. Eight groups of experiments could be simultaneously conducted by the CDL. Therefore, the consistency of the experimental conditions and the accuracy of the experimental results were guaranteed.
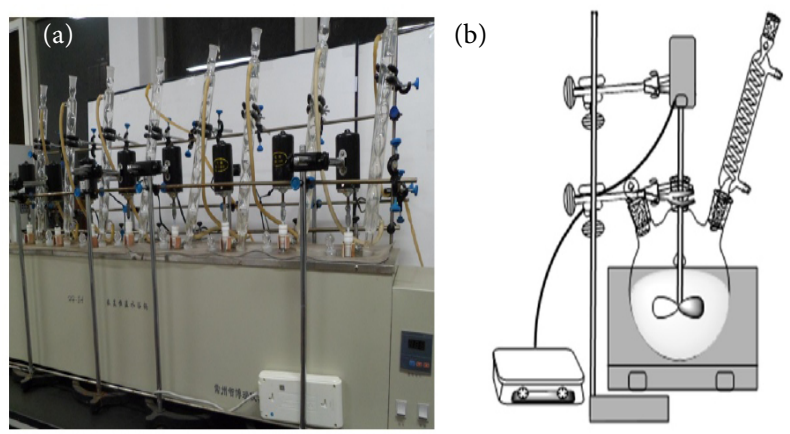

Figure 3: Compound device for leaching: (a) Overall and (b) Structural unit.

When the temperature and rotating speed were well adjusted, $5 \mathrm{~g}$ of ore sample and $1000 \mathrm{~mL}$ of deionised water were placed into the three-mouth flasks for the leaching kinetic experiment. The effects of the factors such as temperature, concentration, stirring speed and particle size, on the dissolution of smithsonite were investigated. For each instance, $5 \mathrm{~mL}$ of solution was extracted using a pipette and filled into a sealed chemical bottle. The solution was subsequently subjected to inductively coupled plasma atomic emission spectroscopy (ICPAES, ICP-1000 II SHIMADZU) to test the zinc concentration at a certain period. Then, the leaching rate $\mathrm{x}$ was calculated.

\section{Results and Discussion}

The zinc oxide ore is mainly composed of smithsonite, and the reaction between the smithsonite and TCA in the aqueous solution could be expressed as:

$2 \mathrm{CCl}_{3} \mathrm{COOH}_{(\mathrm{aq})} \rightarrow 2 \mathrm{H}^{+}{ }_{(\mathrm{aq})}+2 \mathrm{CCl}_{3} \mathrm{COO}^{-}$

$\mathrm{ZnCO}_{3(\mathrm{~s})}+2 \mathrm{H}^{+}{ }_{\text {(aq) }} \rightarrow \mathrm{Zn}^{2+}{ }_{\text {(aq) }}+\mathrm{CO}_{2(\mathrm{~g})}+\mathrm{H}_{2} \mathrm{O}_{(\mathrm{l})}$

$\mathrm{ZnCO}_{3(\mathrm{~s})}+2 \mathrm{CCl}_{3} \mathrm{COOH}_{(\text {aq })} \rightarrow \mathrm{Zn}_{(\text {aq })}^{2+}+2 \mathrm{CCl}_{3} \mathrm{COO}_{(\text {aq })}^{-}+\mathrm{CO}_{2(\mathrm{~g})}+\mathrm{H}_{2} \mathrm{O}_{(\mathrm{l})}$

\section{Effect of temperature}

With ore sample concentration, TCA concentration, average particle size and stirring speed set at $0.5 \%, 0.75 \mathrm{~mol} / \mathrm{L}, d_{85}=50 \mu \mathrm{m}$ and $800 \mathrm{rpm}$, respectively, the temperature effect on zinc leaching rate was investigated. As shown in Figure 4, a remarkable influence of temperature on zinc leaching rate was exhibited. Within the same period, the leaching rate increased as the temperature increased. After $21 \mathrm{~min}$ of leaching, the zinc-leaching rate at $20^{\circ} \mathrm{C}$ was $24.47 \%$, also exhibiting an upward tendency, indicating that the dissolution equilibrium of the smithsonite leaching process was not yet achieved. At $70^{\circ} \mathrm{C}$, the zinc leaching rate reached close to $100 \%$ after $10 \mathrm{~min}$. An increase in temperature sped up the solution molecular motion. The collision chance of the leaching reagent with the mineral was improved.

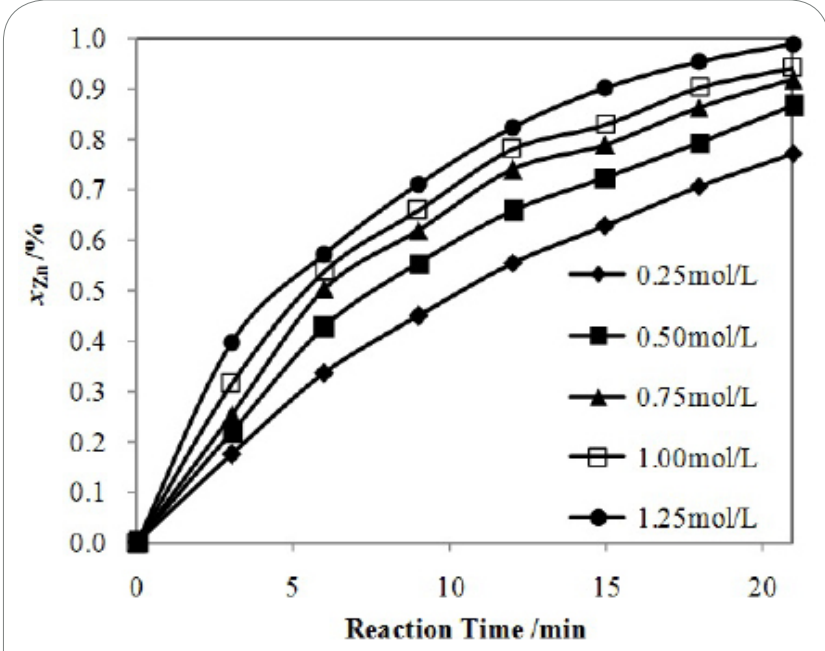

Figure 4: The engineering stress-strain curves of the composites upon (a) quasi-static compression and (b) dynamic compression.

\section{Effect of reagent concentration}

The variation curves of the zinc-leaching rate with TCA concentration are shown in Figure 5. The conditions of the zinc oxide ore sample tested are as follows: $50 \mu \mathrm{m}$ particle size, $0.5 \%$ sample concentration, $40^{\circ} \mathrm{C}$ temperature, $800 \mathrm{rpm}$ stirring speed and $21 \mathrm{~min}$ leaching time. The figure shows that the leaching rate of smithsonite increased with the increase in reagent concentration. The final rate was $73.3 \%$ in $0.25 \mathrm{~mol} / \mathrm{L}$ TCA solution, whereas it reached $84.6 \%$ at 0.5 $\mathrm{mol} / \mathrm{L}$. The zinc leaching rate further increased with increasing TCA concentration. Consequently, the reagent concentration exhibited a significant influence on the leaching of smithsonite.

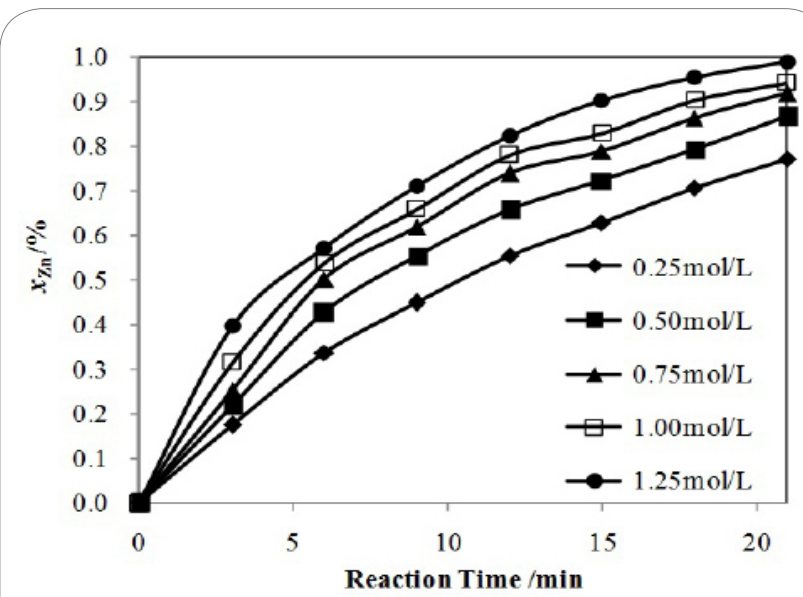

Figure 5: Influence of trichloroacetic acid concentration on zinc leaching rate.

\section{Effect of particle size}

The relationships between the dissolution rate and dissolution time of ore particles with different particle sizes in TCA solution are shown in Figure 6. The sample concentration, temperature, TCA concentration 
and stirring speed were kept constant at $0.5 \%, 40^{\circ} \mathrm{C}, 0.75 \mathrm{~mol} / \mathrm{L}$ and $800 \mathrm{rpm}$, respectively. As seen in Figure 6, the leaching rate increased as the particle size decreased. After leaching for $21 \mathrm{~min}$, the coarsegrading ores exhibited a low leaching rate of only $20 \%$ with ore particle size of $260 \mu \mathrm{m}$. It increased slightly when the particle size decreased to $180 \mu \mathrm{m}$. Moreover, it was $60.40 \%$ at $80 \mu \mathrm{m}$, after which it reached the highest at $50 \mu \mathrm{m}$. Based on the results, the ore particle size variations exhibited a large influence on the dissolution rate of smithsonite. This finding can be attributed to the specific surface area of the mineral particle, which increased with the decrease in particle size. Hence, small particle size is conducive for the leaching agent to get into the mineral gaps, such that the collision chance of the leaching reagent with the mineral particle is improved. The products can easily enter the solution, thereby facilitating the dissolution of smithsonite.

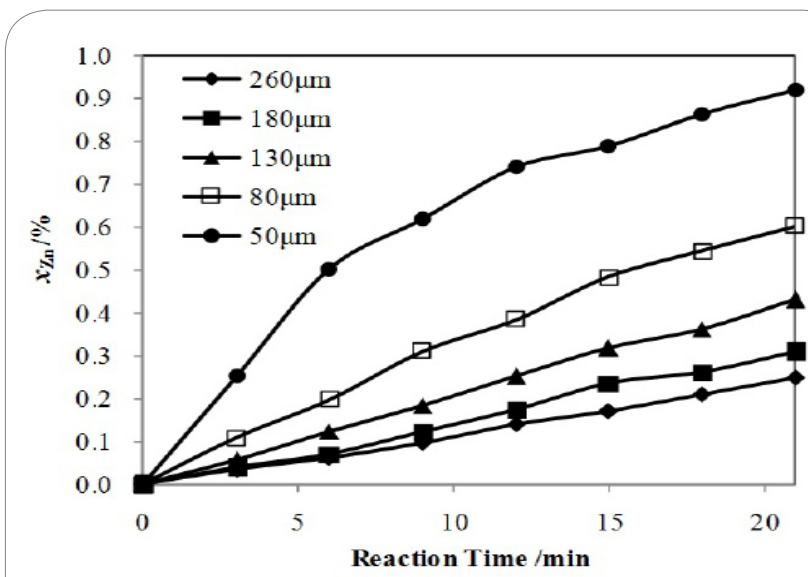

Figure 6: Influence of particle size on zinc leaching rate.

\section{Effect of stirring speed}

To investigate the influence of stirring speed on the dissolution of smithsonite in TCA solution, five different stirring speeds ranging from $200 \mathrm{rpm}$ to $1000 \mathrm{rpm}$ were selected for this experiment. The TCA concentration, average ore particle size and reaction temperature were kept constant at $0.75 \mathrm{~mol} / \mathrm{L}, 50 \mu \mathrm{m}$ and $40^{\circ} \mathrm{C}$, respectively. The results presented in Figure 7 show that the dissolution rates of zinc oxide at different stirring intensities varied only slightly; therefore, the stirring intensity exhibited limited influence on the dissolution of smithsonite in TCA solution. From the kinetic perspective, this observation indicates that the solid and liquid phases could be homogenously mixed in the reactors, and the reaction may be controlled not by diffusion but by chemical reaction.

\section{Dissolution kinetic analysis}

The dissolution reaction of smithsonite in TCA solution is a liquidsolid heterogeneous dissolution reaction. Liquid-solid reactions can be generally classified into three forms: (1) The products are soluble in water, and the solid particle sizes gradually decrease until they completely disappear as the reaction proceeds. (2) The products are solid and adhere to the unreacted core, according to the shrinking core model. (3) The solid reactant disperses in the insoluble gangues, and the liquid one diffuses into the ores through pores and cracks; thus, dissolution occurs simultaneously on both the surface and the interior.

The total reaction equation of the dissolution process can be expressed as follows:

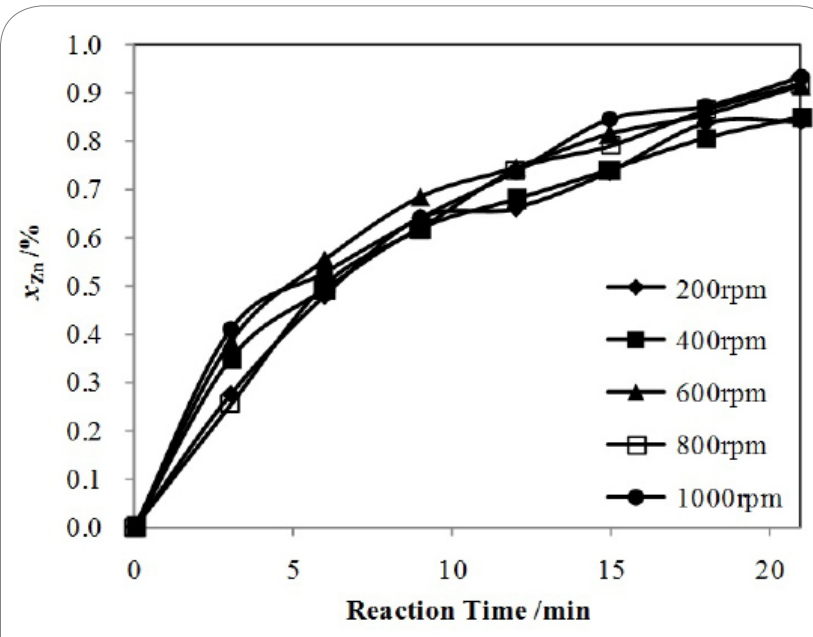

Figure 7: Influence of stirring speed on zinc leaching rate.

$a \mathrm{~A}+b \mathrm{~B}=c \mathrm{C}+d \mathrm{D}$

For a dissolution reaction without any solid product layer, when the leaching agent concentration is kept constant during the reaction, the kinetic equation of leaching process can be generally expressed as $[23,24]$

$1-(1-\mathrm{x})^{1 / \mathrm{FP}}=\left[\mathrm{bk}^{\prime} \mathrm{C}_{\mathrm{A} 0} /\left(a \rho_{\mathrm{B}} r_{0}\right)\right] t$

where $\mathrm{x}$ is the leaching rate; $k^{\prime}$ is the apparent speed constant; $C_{A 0}$ is the initial concentration of leaching reagent $\mathrm{A} ; \rho_{\mathrm{B}}$ is the molar density of the ore particle; $r_{0}$ is the original radius of the ore particle; $F \mathrm{p}$ is the shape factor of the particle; and $a$ and $b$ are the reaction coefficients of the leaching agent $A$ and the ore $B$, respectively. When the leaching reagent concentration varies during the leaching process, the leaching kinetic equation of the single-size fraction system can be generally expressed as $[23,24]$

$[\mathrm{dx}] /[\mathrm{d} t]=\left[\left(3 b k^{\prime} C_{\mathrm{A} 0}\right) /\left(a \rho_{\mathrm{B}} r_{0}\right)\right](1-\mathrm{x})^{2 / 3}(1-a \sigma x / b)$

where $\sigma$ is a constant related to single-size fraction, average-size fraction or multiple-size fraction, and $\sigma=\mathrm{n}_{\mathrm{B} 0} /\left(\mathrm{C}_{\mathrm{A} 0} V\right)$.

The value of $\mathrm{n}$ is related to the particle size of the initial solid reactant $\mathrm{B}_{0}$.

For leaching reactions that generated solid products, the rate equation of leaching kinetics can be divided into the following forms:

If the total leaching rate is controlled by the diffusion of the liquid boundary layer, the kinetic equation is presented by the following equation $[23,24]$.

$\left.\mathrm{x}=3 b D_{\mathrm{L}} C_{\mathrm{A} 0} /\left(a \sigma \rho_{\mathrm{B}} r_{0}\right)\right] t$

where $D_{\text {L }}$ and 6 are the effective diffusion coefficient and the thickness of the liquid boundary layer, respectively.

If the total rate is determined by the interior diffusion rate of the solid product layer, the kinetic equation can be expressed as $[23,24]$

$\left.1-2 / 3 \mathrm{x}-(1-\mathrm{x})^{2 / 3}=2 b D_{\mathrm{S}} C_{\mathrm{A} 0} /\left(a \rho_{\mathrm{B}} r_{0}^{2}\right)\right] t$ 
Citation: Deng J, Sun Q, Lin P, Song G, Wen S, et al. (2015) Dissolution Kinetics of Zinc Oxide Ore with an Organic Acid. Int J Metall Mater Eng 1: 109. doi: http://dx.doi.org/10.15344/2455-2372/2015/109

Page 5 of 7

where DS is the effective diffusion coefficient of the solid product layer.

If the total reaction rate is determined by the chemical reaction rate, the kinetic equation is $[23,24]$

$\left.1-(1-\mathrm{x})^{1 / 3}=b k \mathrm{rr} C_{\mathrm{A} 0} /\left(a \rho_{\mathrm{B}} r_{0}\right)\right] t$

where $\mathrm{kr}$ is the speed constant of the interface chemical reaction.

Moreover, the hybrid control of those above has a leaching rate equation expressed as [23-25]

$1 / 3 \ln (1-\mathrm{x})+\left[(1-\mathrm{x})^{-1 / 3}-1\right]=k t$

Additionally, the volume reaction model can be grouped into regular pore model, homogeneous model, random pore model, particle pore model, and so on $[23,24,26,27]$, all of which are not suitable to be applied as the kinetic model in this experiment based on their applicable conditions.

In accordance with the particle characteristics and SEM morphology of the ore, the experimental particles could be approximated to be spherical, with a shape factor of $\mathrm{Fp}=3$. Given that the stirring speed almost has no influence on the dissolution of smithsonite, the external diffusion control could be excluded. Thus, the reaction equation (11) could be defined and subsequently fitted. Furthermore, the correlations between the experimental data and other reaction models were investigated, as shown in Table 2.
The correlation coefficients obtained based on the surface chemical reaction controlling model all exceeded 0.99. According to Eq. 11, the reaction was controlled by chemical reaction.

In accordance with Eq. (11), the variation curves of $1-(1-\mathrm{x})^{1 / 3}$ with time $t$ at different temperatures were plotted in Figure 8(a), showing a favourably linear relationship. This result suggests that the dissolution process of the smithsonite in the TCA solution was indeed controlled by chemical reaction.

To determine the influences of TCA concentration, temperature and ore particle size on the leaching kinetics of smithsonite, the following semi-empirical model was eventually established:

$1-(1-\mathrm{x})^{1 / 3}=\left[k_{0} \cdot\left(C_{\mathrm{TCA}}\right)^{\alpha} \cdot(P)^{\beta} \exp (-E / R T)\right] t$

where $k_{0}$ is the pre-exponential factor; and C, P, E, R and T represent the reagent concentration, the ore particle size, the activation energy, the universal gas constant and the thermodynamic temperature, respectively.

When only the TCA concentration is varied and others are unchanged, Eq. (12) can be expressed as

$1-(1-\mathrm{x})^{1 / 3}=k_{0} \cdot\left(C_{\mathrm{TCA}}\right)^{\alpha} t$

$d\left[1-(1-x)^{1 / 3}\right] / d t=k_{0} \cdot\left(C_{T C A}\right)^{\alpha}$

\begin{tabular}{|c|c|c|c|c|c|c|}
\hline \multirow[t]{3}{*}{ Parameter } & \multicolumn{2}{|c|}{ Diffusion through the liquid film } & \multicolumn{2}{|c|}{ Diffusion through the product layer } & \multicolumn{2}{|c|}{ Surface chemical reaction } \\
\hline & \multicolumn{2}{|l|}{$\mathrm{x}$} & \multicolumn{2}{|c|}{$1-3(1-x)^{2 / 3}+2(1-x)$} & \multicolumn{2}{|l|}{$1-(1-x)^{1 / 3}$} \\
\hline & $\mathrm{kd}\left(\min ^{-1}\right)$ & $\mathrm{R}^{2}$ & $\mathrm{kl}\left(\min ^{-1}\right)$ & $\mathrm{R}^{2}$ & $k r\left(\min ^{-1}\right)$ & $\mathrm{R}^{2}$ \\
\hline \multicolumn{7}{|l|}{$T /{ }^{\circ} \mathrm{C}$} \\
\hline 20 & 0.020 & 0.978 & 0.003 & 0.930 & 0.008 & 0.990 \\
\hline 30 & 0.029 & 0.966 & 0.009 & 0.970 & 0.013 & 0.992 \\
\hline 40 & 0.004 & 0.911 & 0.029 & 0.983 & 0.026 & 0.990 \\
\hline 50 & 0.044 & 0.826 & 0.052 & 0.982 & 0.045 & 0.997 \\
\hline 60 & 0.081 & 0.874 & 0.088 & 0.973 & 0.081 & 0.994 \\
\hline \multicolumn{7}{|l|}{$\mathrm{C} / \mathrm{mol} / \mathrm{L}$} \\
\hline 0.25 & 0.037 & 0.976 & 0.012 & 0.922 & 0.018 & 0.997 \\
\hline 0.50 & 0.039 & 0.938 & 0.023 & 0.974 & 0.022 & 0.993 \\
\hline 0.75 & 0.041 & 0.911 & $0 . .029$ & 0.983 & 0.026 & 0.990 \\
\hline 1.00 & 0.041 & 0.893 & 0.032 & 0.987 & 0.028 & 0.990 \\
\hline 1.25 & 0.049 & 0.896 & 0.042 & 0.982 & 0.035 & 0.995 \\
\hline \multicolumn{7}{|l|}{$P / \mu \mathrm{m}$} \\
\hline 260 & 0.010 & 0.979 & 0.001 & 0.850 & 0.004 & 0.996 \\
\hline 180 & 0.015 & 0.993 & 0.001 & 0.914 & 0.008 & 0.997 \\
\hline 130 & 0.020 & 0.998 & 0.003 & 0.912 & 0.005 & 0.992 \\
\hline 80 & 0.029 & 0.990 & 0.008 & 0.943 & 0.012 & 0.998 \\
\hline 50 & 0.046 & 0.924 & 0.029 & 0.983 & 0.026 & 0.990 \\
\hline
\end{tabular}

Table 2: Apparent rate constants and correlation coefficients of different kinetic models.

$1-(1-\mathrm{x})^{1 / 3}=\left[b k^{\prime} C_{\mathrm{A} 0} /\left(a \rho_{\mathrm{B}} r_{0}\right)\right] t$

The statistical data based on multiple models revealed that the dissolution reaction of smithsonite in the TCA solution was controlled by neither the liquid film diffusion nor the product layer diffusion.
For Eqs. (13) and (14), the relation curves between $1-(1-\mathrm{x})^{1 / 3}$ and time $t$ under different TCA concentrations were eventually drawn, as plotted in Figure 8(b). The slopes correspond to the values of d[1-(1$\left.\mathrm{x})^{1 / 3}\right] / \mathrm{dt}$ under different TCA concentrations. The $\ln \left[\mathrm{d}\left[1-(1-\mathrm{x})^{1 / 3}\right] /\right] /$ $\mathrm{dt}]$ - $\ln C$ curves are plotted in Figure 9(a), with the slope $\alpha$ calculated as 
Citation: Deng J, Sun Q, Lin P, Song G, Wen S, et al. (2015) Dissolution Kinetics of Zinc Oxide Ore with an Organic Acid. Int J Metall Mater Eng 1: 109. doi: http://dx.doi.org/10.15344/2455-2372/2015/109

0.384. Likewise, the relation curves between $1-(1-\mathrm{x})^{1 / 3}$ and time $\mathrm{t}$ under different particle sizes were also drawn, as plotted in Figure $8(\mathrm{c})$. The curves between $\ln \left[\mathrm{d}\left[1-(1-\mathrm{x})^{1 / 3}\right] / \mathrm{dt}\right.$ and $\ln \mathrm{P}$ were plotted in Figure 9(b), with the slope calculated as $\beta=0.969$.

(a)

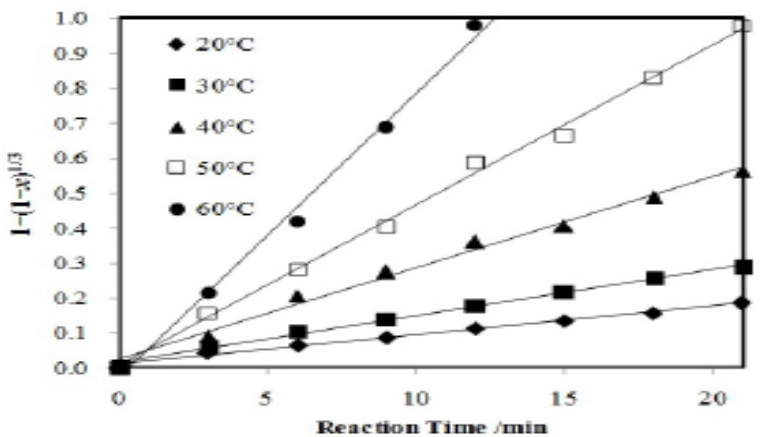

(b)

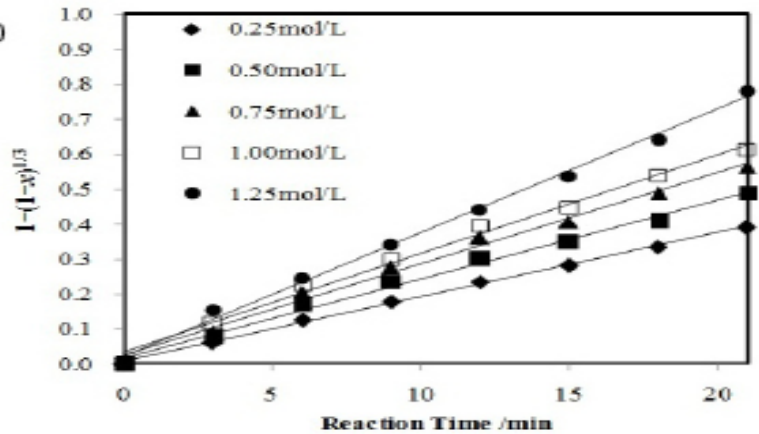

(c)

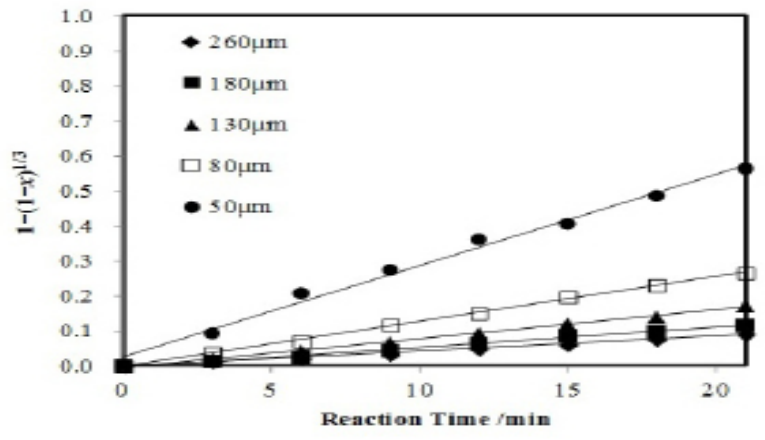

Figure 8: Relation curves between $1-(1-\mathrm{x})^{1 / 3}$ and time $t$ under different influencing factors: (a) Temperature; (b) Reagent concentration; (c) Particle size.

(a)

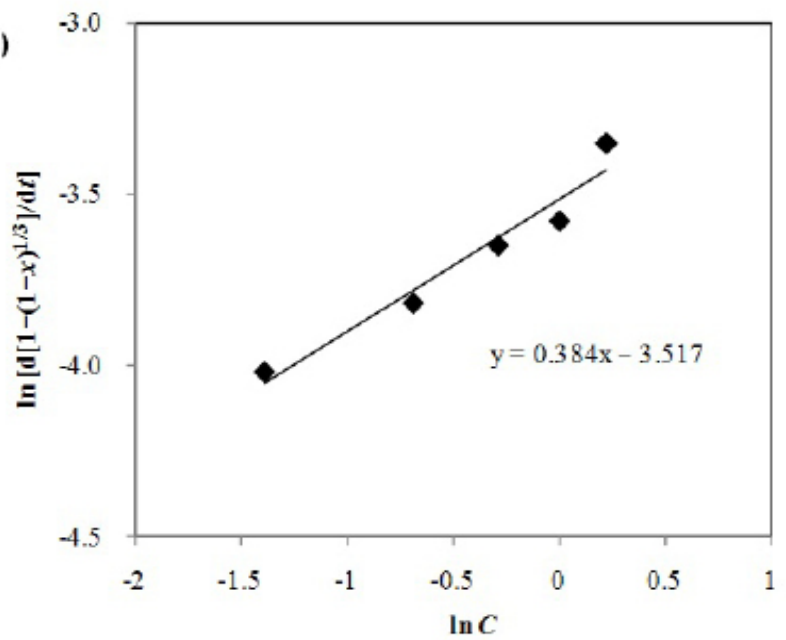

(b)

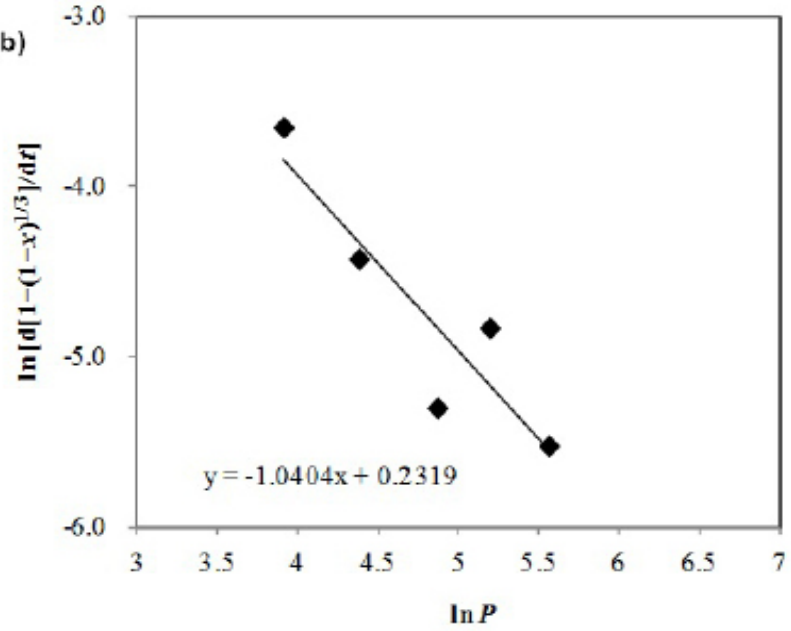

Figure 9: Relation curves between $\ln \left[\mathrm{d}\left[1-(1-\mathrm{x})^{1 / 3}\right] / \mathrm{dt}\right]$ and $\ln \mathrm{C}$, as well as $\ln \mathrm{P}$ (a) TCA concentration; (b) Particle size.

Thus, the dissolution kinetic equation of smithsonite in the TCA solution could be depicted as

$1-(1-\mathrm{x})^{-1 / 3}=\left[k_{0}(C)^{0.384}(P)^{0.969} \exp (-E / R T)\right] \mathrm{t}$

\section{Activation energy}

The temperature dependence of the chemical reaction could be given by Arrhenius equation as follows:

$\ln k=\ln k_{0}-E / R T$
For Eq. (16), $\ln k-1 / T$ is supposed to be a straight line with slope of $-E / R$ and intercept of $\ln k_{0}$, as plotted in Figure 10. The experimental data conformed to Arrhenius equation, and the corresponding apparent activation energy for the dissolution of smithsonite in TCA solution was calculated as $47.61 \mathrm{~kJ} / \mathrm{mol}$. The observations further demonstrated the chemical reaction control on smithsonite dissolution. Subsequently, the values of $\alpha, \beta$ and $E$ were substituted into Eq. (15), obtaining $k_{0}=0.0002 \mathrm{~min}^{-1}$ as the statistical average.

Consequently, the dissolution kinetic equation of smithsonite in the TCA solution could be established as 
Citation: Deng J, Sun Q, Lin P, Song G, Wen S, et al. (2015) Dissolution Kinetics of Zinc Oxide Ore with an Organic Acid. Int J Metall Mater Eng 1: 109. doi: http://dx.doi.org/10.15344/2455-2372/2015/109

Page 7 of 7

$1-(1-\mathrm{x})^{-1 / 3}=\left[0.0002(C)^{0.384}(P)^{-1.0404} \exp (-5726 T)\right] t$

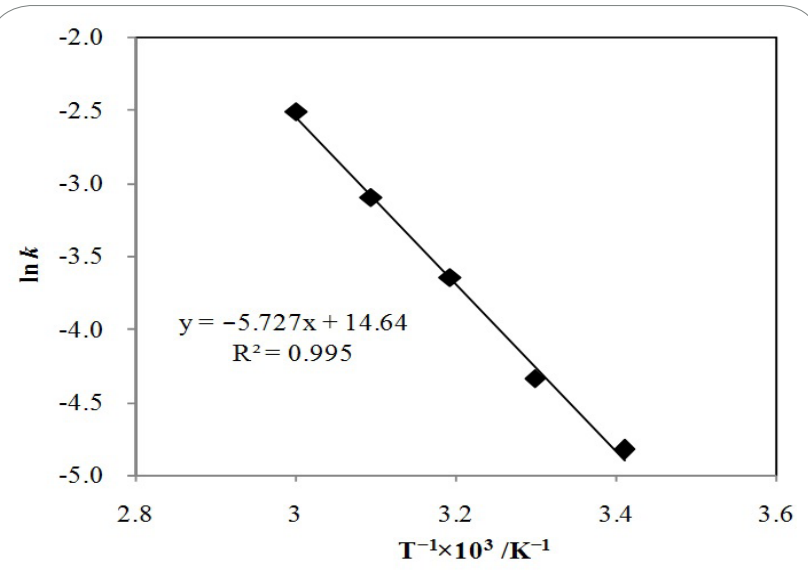

Figure 10: Arrhenius curves for TCA leaching of smithsonite.

\section{Conclusion}

In this study, the dissolution kinetics of smithsonite, an alternative resource of zinc oxide, in trichloroacetic acid solution was investigated, together with its influencing factors. TCA can be derived from industrial waste in the pharmaceutical, biotechnology and chemical fields. The waste acid can be used for recovery of zinc. Finally, the following conclusions were obtained:

1. The dissolution rate of smithsonite in the TCA solution was not restrained by the stirring speed, which suggested that it was not controlled by the diffusion of the solution phase.

2. The apparent activation energy of the reaction was $47.61 \mathrm{~kJ} /$ mol. The reaction rate exhibited great sensitivity at temperatures within $20^{\circ} \mathrm{C}$ to $60^{\circ} \mathrm{C}$, that is, temperature had a large influence on the reaction rate. Moreover, with TCA concentrations ranging from $0.25 \mathrm{~mol} / \mathrm{L}$ to $1.25 \mathrm{~mol} / \mathrm{L}$, an increase in TCA concentration facilitated the dissolution of smithsonite. Furthermore, the dissolution rate increased with the decrease in ore particle size. Finally, the reaction kinetic model associated with the principal influencing factors was eventually constructed as $1-(1-\mathrm{x})^{-1 / 3}=$ $\left[0.0002(C)^{0.384}(P)^{0.969} \exp (-5726 T)\right] t$.

3. Overall, a high reaction speed of smithsonite was exhibited in the TCA solution, indicating that TCA has a dissolving effect on zinc oxide ores, and therefore, can be applied as an advantageous organic leaching reagent.

\section{Competing Interests}

The authors have declared that no competing interests exist.

\section{Author Contributions}

All the authors substantially contributed to the study conception and design as well as the acquisition and interpretation of the data and drafting the manuscript.

\section{Funding}

This work was financially supported by the National Natural Science Foundation of China (Nos. 51168020, 51404119, and 51464029), the Natural Science Foundation of Education Department of Yunnan Province of China (No. 2014Y084), and the Excellent Doctoral Dissertation, Innovative Planning and Talent Cultivation Foundation of Kunming University of Science and Technology (Nos. 41118011 and 201421066).

\section{Reference}

1. Tong X, Song S, He J, Rao F, Lopez-Valdivieso A (2007) Activation of highiron marmatite in froth flotation by ammoniacal copper(II) solution. Miner Eng 20: 259-263.

2. Robert JL, Gaspérin M (1985) Crystal structure refinement of hendricksite, A Zn- and Mn-rich trioctahedral potassium mica: A contribution to the crystal chemistry of zinc-bearing minerals. Tschermaks mineralogische und petrographische Mitteilungen 34: 1-14.

3. Espiari S, Rashchi F, Sadrnezhaad S (2006) Hydrometallurgical treatment of tailings with high zinc content. Hydrometallur 82: 54-62.

4. Duan X-m, Luo $L$ (2000) Review on present situation of the flotation of oxidized zinc ore Mining and Metallurgy, 9, 47 (2000).

5. Zhao Y, Stanforth R (2000) Production of Zn powder by alkaline treatment of smithsonite $\mathrm{Zn}-\mathrm{Pb}$ ores. Hydrometallur 56: 237-249.

6. Hurşit M, Laçin O, Saraç H (2009) Dissolution kinetics of smithsonite ore as an alternative zinc source with an organic leach reagent $J$ Taiwan Inst Chem Eng 40: 6-12

7. Chen A, Jia X, Long S, Huo G, Chen X (2009) Alkaline leaching Zn and its concomitant metals from refractory hemimorphite zinc oxide ore. Hydrometallur 97: 228-232.

8. Qin WZ, Li ZY(2007) Lan and G.Z. Quu, Simulated small-scale pilot plant heap leaching of low-grade oxide zinc ore with integrated selective extraction of zinc. Miner Eng 20: 694-700.

9. Abdel-Aal E (2000) Kinetics of sulfuric acid leaching of low-grade zinc silicate ore. Hydrometallurgy 55: 247-254.

10. Frenay $\mathrm{J}(1985)$ Leaching of oxidized zinc ores in various media. Hydrometallurgy 15: 243-253.

11. Langová S, Leško J, Matýsek D (2009) Selective leaching of zinc from zinc ferrite with hydrochloric acid. Hydrometallurgy 95: 179-182.

12. Nunez C, Viñals J (1984) Kinetics of leaching of zinc ferrite in aqueous hydrochloric acid solutions. Metall Trans B 15: 221-228.

13. Bakan F, Laçin O, Bayrak B, Saraç $H$ (2006) Dissolution kinetics of natural magnesite in lactic acid solutions. Int J Miner Process 80: 27-34

14. Shabani M, Irannajad M, Azadmehr A (2012) Investigation on leaching of malachite by citric acid. Int J Miner Metall Mater 19: 782-786.

15. Habbache N, Alane N, Djerad S, Tifouti L (2009) Leaching of copper oxide with different acid solutions Chem Eng J 152: 503-508.

16. Demir F, Dönmez B, Çolak S (2003) J Chem Eng Jpn 36: 683

17. Laçin O, Dönmez B, Demir F (2005) Dissolution kinetics of natural magnesite in acetic acid solutions Int J Miner Process 75: 91-99.

18. Demirkıran N, Ekmekyapar A, Künkül A, Baysar A (2007) A kinetic study of copper cementation with zinc in aqueous solutions. Int J Miner Process 82: $80-85$

19. Yvon M, Chabanet C, Pelissier JP (1989) Solubility of peptides in trichloroacetic acid (TCA) solutions Hypothesis on the precipitation mechanism. Int J Pept Protein Res 34: 166 (1989).

20. Juuti S, Norokorpi Y, Ruuskanen J (1995) Trichloroacetic acid (TCA) in pine needles caused by atmospheric emissions of kraft pulp mills. Chemosphere 30: 439-448.

21. Ju S, Motang T, Shenghai $Y$, Yingnian $L$ (2005) Dissolution kinetics of smithsonite ore in ammonium chloride solution. Hydrometallurgy 80: 67-74.

22. Thomas BK, Fray DJ (1981) Leaching of oxidic zinc materials with chlorine and chlorine hydrate. Metal Trans B 12: 281-285.

23. Hua $Y$ (2004) Metallurgical process kinetics, Metallurgical industry press, Beijing.

24. Szekely J (1976) Gas-solid reactions Academic Press.

25. Bingöl MD, Canbazoğlu, Aydoğan S (2005) Dissolution kinetics of malachite in ammonia/ammonium carbonate leaching. Hydrometallurgy 76: 55-62.

26. Georgiou D, Papangelakis V (1998) Sulphuric acid pressure leaching of a limonitic laterite: chemistry and kinetics. Hydrometallurgy 49: 23-46.

27. Bhatia S, Vartak B (1996) Reaction of microporous solids: The discrete random pore model. Carbon 34: 1383-1391. 